\title{
Research on Current Situation of Comprehensive Evaluation of Power Grid in China
}

\author{
Zhendong Du ${ }^{1, a}$, Hua Weng ${ }^{1, b}$, Dongxiao $\mathrm{Niu}^{2, \mathrm{c}}$, Hongfei Liu ${ }^{2, \mathrm{~d}}$, Yali \\ Huang $^{2,}$, Han Wu ${ }^{2, f}$ \\ ${ }^{1}$ Economy research institute, State Grid Zhejiang Electric Power Company, Hangzhou, Zhejiang \\ 310000 \\ ${ }^{2}$ School of economics and management, North China Electric Power University, Changping District, \\ Beijing 102206 \\ aemail: hzdzd@163.com, bemail: wenghua1986@163.com, ${ }^{c} e m a i l:$ niudx@126.com,

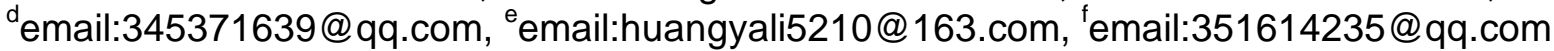

Keywords:Power grid comprehensive evaluation, Evaluation index system, Comprehensive evaluation method

Abstract. The reasonable and accurate assessment of the development level of the power grid is very important for a country's power grid construction and power distribution. The domestic and foreign power grid assessment index system, grid comprehensive evaluation methods are summarized in this paper, expounds the more commonly used network evaluation index system construction method, grid comprehensive evaluation method, and at the conclusion of the current grid comprehensive evaluation problems based on, and pointed out the direction for the comprehensive evaluation of the power grid.

\section{Introduction}

At present, our country is still in the stage of economic development. Power system infrastructure construction is still facing tremendous pressure. Power grid planning and decision-making are the premise of power system infrastructure, although in recent years in power project comprehensive optimization and decision method has certain research results, but these optimization methods are in clear candidate project based on decision analysis, leading to the project decision-making level is low, power grid construction and transformation of the targeted enough ${ }^{[1]}$. The grid evaluation can provide an important basis for planning and decision-making, and is a necessary condition for good planning and decision making. Therefore, under the environment of power system reform, how to help the Power Grid Corporation in grid project construction and power grid renovation process in the weak link and on the actual situation of power grid are objective, effective and comprehensive assessment, so as to grid in grid project construction and power grid renovation process to provide information and support, to meet the needs of national economic and social development, improve power project decision making for and the efficiency in the use of funds, and is the power grid effectively evaluate a urgent need to address the issue.

In the assessment of the power system, it is necessary to include two parts, both the evaluation system of the power grid and the evaluation method of the power grid. Power grid assessment level, the quality of the pros and cons of the above are usually the two aspects of the content of the decision. Literature [2] summarize the domestic and international smart grid statistics index construction and put forward the smart grid statistical index system of research ideas and system construction principle, Literature [3] introduce a comparative analysis of the research results of the smart grid power system in different areas or aspects of the comprehensive evaluation model and method in recent years, Literature [4] in view of the actual situation of China's smart grid construction established strong and smart grid comprehensive evaluation index system and puts forward three kinds of smart grid evaluation method, the evaluation system of the smart grid to in-depth study and discussion. Based on the goal of power network planning, the paper aims to evaluate the planning of power grid system from five aspects: power supply security, reliability, economy, adaptability and coordination ${ }^{[5]}$. In addition, grid evaluation content, from the view of the safety of power grid, started to build up a network 
security assessment system ${ }^{[6-10]}$, the construction of the power quality evaluation system ${ }^{[11-17]}$. From the point of view of sustainable development of the power grid of constructing network evaluation system for integrated development of cells from the point of view of the quality of power supply ${ }^{[18-20]}$. The content of the grid assessment has certain guiding significance to the reality, but the evaluation content is not comprehensive, can not meet the requirements of the new electric power system evaluation.

In this paper, firstly, discusses the current situation of domestic and foreign evaluation index system of power grid, Then, the comprehensive evaluation methods used in the evaluation of domestic and foreign power grid development are reviewed and analyzed. Finally, some problems in the evaluation of the development level of power grid are discussed, and the next step in the field of power network evaluation is proposed.

\section{Research on evaluation index system of power grid}

By reading the literatures found in grid construction of evaluation index system in the process, usually need to go through, determine the evaluation object, clear index range, the index analysis, index selection, index analysis, indicators show six steps to complete the construction of index system. Among them, the index selection and index analysis is the key to constitute the index system.

\section{Research on index selection}

The establishment of evaluation index system determines the level of the evaluation of the power grid, and in the construction of evaluation index system, the selection of indicators is particularly important. Therefore, the scholars at home and abroad on how to choose the appropriate method of key indicators also carried out a lot of research work.

On the selection of indicators, there are mainly qualitative indicators and quantitative indicators, macro demand indicators and micro evaluation indicators, the selection method of the two types of indicators. In addition, a large number of documents on the previous indicators selection approach based on, index selection for the types of indicators ${ }^{[21-26]}$ and proposed in the literature [27] index type, performance evaluation indicators, technology supporting index and effect evaluation index are not beyond the two types of index selection range.

1) According to the nature of indicators, the indicators can be divided into two categories: qualitative and quantitative indicators, such as table 1. Qualitative indicators to choose the direction and direction of indicators, quantitative indicators for in-depth analysis and analysis of indicators, and according to the actual situation, the establishment of tree structure and other power grid evaluation index system ${ }^{[28]}$.

Table.1 Analysis of qualitative index and quantitative index

\begin{tabular}{|c|c|c|c|}
\hline & The characteristics of index & $\begin{array}{l}\text { Selection } \\
\text { principle }\end{array}$ & Index example \\
\hline $\begin{array}{l}\text { Qualitative } \\
\text { index }\end{array}$ & $\begin{array}{l}\text { 1. Usually in the selection of indicators to play the } \\
\text { role of the direction and scope of the selected } \\
\text { indicators } \\
2 \text {. There is no fixed formula and data source }\end{array}$ & $\begin{array}{l}1 . \\
\text { Systematicness } \\
\text { 2. Independence } \\
\text { 3. Scientific } \\
\text { nature }\end{array}$ & $\begin{array}{l}\text { 1. Safety index } \\
\text { 2. Economic index } \\
\text { 3. Quality index } \\
\text { 4. Cleaning index }\end{array}$ \\
\hline $\begin{array}{l}\text { Quantitative } \\
\text { index }\end{array}$ & $\begin{array}{l}\text { 1. Usually play a role in further decomposition } \\
\text { and analysis in index selection work } \\
\text { 2. Has a fixed calculation method, formula and } \\
\text { data sources }\end{array}$ & $\begin{array}{l}\text { 1. Testability } \\
\text { 2. Clearly } \\
\text { 3. Timeliness } \\
\text { 4. Consistency }\end{array}$ & $\begin{array}{l}\text { 1. Safety accident } \\
\text { 2. Secondary circuit } \\
\text { 3. Power angle stability } \\
\text { 4. Voltage qualification } \\
\text { rate } \\
\text { 5. Line loss rate } \\
\text { 6. Voltage qualification } \\
\text { rate }\end{array}$ \\
\hline
\end{tabular}

2) According to the demand and evaluation of indicators, the indicators can be divided into two categories, including macro demand indicators and micro evaluation indicators. The indicators are 
shown in table 2. According to the index system of the macro demand index and micro assessment index is constructed for smart grid comprehensive evaluation system, including between two kinds of index sets exist certain causal relationship, the macro demand index reflects the is on the grid core value assessment; micro assessment index reflects is evaluation of power grid operation state and the development of the construction ${ }^{[29]}$.

Table.2 Comparison of macro demand index and micro evaluation index

\begin{tabular}{|c|c|c|c|}
\hline & The characteristics of index & Selection principle & Index example \\
\hline $\begin{array}{l}\text { Macro } \\
\text { demand } \\
\text { index }\end{array}$ & $\begin{array}{l}\text { 1. Response to the overall } \\
\text { development of the power grid, } \\
\text { as a result of micro assessment } \\
\text { indicators } \\
\text { 2. In essence, it is a measure of } \\
\text { the degree of satisfaction of the } \\
\text { needs of the stakeholders of the } \\
\text { power grid }\end{array}$ & $\begin{array}{l}\text { According to Maslow's hierarchy of } \\
\text { needs theory, it is not satisfied with the } \\
\text { degree of severity of the consequences } \\
\text { of the power grid to divide the } \\
\text { stakeholders, and then determine the } \\
\text { corresponding indicators }\end{array}$ & $\begin{array}{l}\text { 1. The basic } \\
\text { demand index } \\
\text { 2. Reliability } \\
\text { demand index } \\
\text { 3. Coordination } \\
\text { demand index } \\
\text { 4. Economic } \\
\text { demand index }\end{array}$ \\
\hline $\begin{array}{c}\text { Micro } \\
\text { evaluation } \\
\text { index }\end{array}$ & $\begin{array}{l}\text { 1. The operation status of the } \\
\text { power grid and the problems } \\
\text { existing in the development and } \\
\text { construction are the reasons for } \\
\text { the macro demand indicators. } \\
\text { 2. In essence, the further } \\
\text { decomposition and } \\
\text { transformation of macro demand } \\
\text { indicators }\end{array}$ & $\begin{array}{l}\text { 1. The demand index of the macro } \\
\text { demand index is used as a characteristic } \\
\text { of the power grid } \\
2 \text {. The characteristics of the } \\
\text { decomposition, transformation, the } \\
\text { formation of the corresponding } \\
\text { evaluation index set }\end{array}$ & $\begin{array}{l}\text { 1. The contact rate } \\
\text { of medium voltage } \\
\text { power line } \\
\text { 2. "N-1" pass rate } \\
\text { 3. The intact rate } \\
\text { of line } \\
\text { 4. Information } \\
\text { system integration }\end{array}$ \\
\hline
\end{tabular}

\section{Study on index system}

Through reading the literature, we found that the evaluation index system is mainly from 3 dimensions: the security of the power grid, the quality of the power supply and the sustainable development of the power grid. In addition, under the new environment of the electricity reform, electricity reform is to foster market players, perfect the market mechanism to allow the market to play a decisive role in the configuration of power resources ${ }^{[30]}$. Therefore, in addition to the above evaluation system grid three dimensions, it should also add the effectiveness of the grid operator, which is content assessment grid, power grid safety, quality of power supply, the sustainable development of the grid and grid operators for the benefit of the four basic dimensions.

(1) Power grid security evaluation

Network security refers to the operation of the electric power equipment must be in no more than their allows operation within the current, voltage and frequency of the amplitude and the time limit, the consequences of unsafe may cause damage to electrical equipment, and even bring power personnel casualties $^{[31]}$. In network security assessment research, Jun Hua Ma proposed the basic concepts of rough set relationship and attribute reduction algorithm, through the theory of electrical engineering calculation cascading failure diagnosis of early warning system of attribute values, establish timely fault diagnosis and early warning of safety analysis model ${ }^{[6]}$. Literatures [7-10] proposed in the construction of power grid security evaluation system, should include 4 aspects of the network structure security, power grid operation security, adequacy and reliability.

(2) Power quality evaluation

Power quality is an important aspect of the development of power grid, especially happening at home and abroad, several major blackouts are strengthening the scholars on the power grid emergency response capability, reliability and power quality, the degree of concern. Generally speaking, the research on power supply quality in China can be divided into two aspects. One is the research on the power quality of the power supply, which are the research on the reliability of power supply ${ }^{[32,33]}$.

1) Aiming at the power quality of power network, it is mainly focused on the two aspects of power quality monitoring and evaluation. To improve the power to quality and better manage the distribution network electric energy quality problems, realize real-time monitoring of the power quality, based on 
the LabVIEW is adopted to establish the electric energy quality monitoring system, the distribution network power quality detection and analysis software have been developed ${ }^{[1,12]}$.

2) In view of the reliability of the power grid in the presence of large amounts of data, can be roughly divided into micro grid reliability, the reliability of transmission network research and distribution network reliability research, most of them focus on the assessment and prediction on the reliability of power. Due to the different evaluation models and different consideration, there are some differences in the methods of power grid reliability assessment proposed by the relevant scholars. Such as the power grid reliability evaluation model based on support vector machine, the maximum load, the average segment number, average power switch contact switch units, overhead lines, the average length of each line with the average variable and line average distribution capacity as model input, power supply reliability rate as the output of the model ${ }^{[15]}$.

(3) Assessment of sustainable development of power grid

In recent years, with China to build a resource conserving and environment friendly society attention, and promote the sustainable development of attention, the grid research also began to pay attention to the research on the sustainable development of the power grid, and the sustainable development of the power grid as grid rating assessment is an important content. Sustainable development plays an important role in the construction of power grid, theoretically in the power grid construction project must perfect management system, and resolutely fulfill the environmental approval procedures, and actively promote the power grid construction project environmental assessment and acceptance of environmental protection work; grid sustainable development and economic development, technology, quality of the national economy, environment and resources protection an important link in the construction of power grid enterprise sustainable development system, it is necessary to consider these factors; comprehensive use of objective pertinence, scientific system and maneuverability as constraints to construct grid development evaluation system, provides a new direction for the sustainable development of power grid $^{[18-20]}$.

(4) Power grid operation benefit evaluation

Under the environment of electricity reform, new electricity reform program will according to "restrain intermediate, release the power system structure on both sides", it is recommended to" open, independent and three strengthen "[34]. Before the introduction of the new electricity reform program, the relevant field experts have done the relevant research on the economy of the power grid. Literature [35] introduced cash flow model, net present value, internal return rate and investment recovery period, the sensitivity analysis of power grid planning in economic evaluation of commonly used methods, and points out that in the competitive market environment, uncertain economic evaluation method research and make the electric network planning project post evaluation work importance. Literature [36] in considering the power supply reliability degree of economic value to the user side effects based on the proposed a new power grid planning cost benefit analysis and evaluation of the mathematical model, and has carried on the analysis and evaluation of the planning scheme, to further improve the cost benefit analysis method applied in the construction of the power grid planning. Literature [37] stand in the angle of power grid enterprise, conducts the research to the power grid enterprise performance evaluation index system using fuzzy analytic hierarchy process (AHP), provides some references and helps for the improvement of power grid enterprise operation performance and its long-term development.

(5) Other aspects of content

In the power grid comprehensive evaluation system established, in addition to the above four basic aspects of content, according to the different needs of evaluation object and evaluation object and need to appropriately increase the other contents to realize adaptive grid assessment, such as technical rationality, dimensional support level, adaptability and coordination, power grid planning and construction of power grids, power equipment, power grid low carbon benefits, network structure, load supply capacity, management level, the level of technology and equipment ${ }^{[38-40]}$. 


\section{Research on comprehensive evaluation method of power grid in China}

Power grid evaluation method includes the method of determining the index weight and the method of comprehensive evaluation.

(1) Method for determining index weight

1) In the research of evaluation system of power grid, the subjective weighting method, the objective weight method and the subjective and objective weight method are the main methods to evaluate the weight of the index. Three weighting methods are compared as shown in table 3.

Tables.3 Comparison of methods for determining weight of index

\begin{tabular}{cll}
\hline $\begin{array}{c}\text { Method of } \\
\text { weighting }\end{array}$ & \multicolumn{1}{c}{ Overview of methods } & \multicolumn{1}{c}{ Typical methods and characteristics } \\
\hline $\begin{array}{c}\text { Subjective } \\
\text { weighting } \\
\text { method }\end{array}$ & $\begin{array}{l}\text { Make use of the experience of senior experts in } \\
\text { the field of industry, to judge the relative } \\
\text { importance of evaluation indicators, and then } \\
\text { determine the weight }\end{array}$ & $\begin{array}{l}\text { Analytic hierarchy process: qualitative } \\
\text { analysis of the logical relationship between } \\
\text { indicators, can be fully compatible with } \\
\text { different categories of indicators, to achieve } \\
\text { the desired objectives of evaluation }\end{array}$ \\
\hline $\begin{array}{c}\text { Objective } \\
\text { weighting } \\
\text { method }\end{array}$ & $\begin{array}{l}\text { The weight coefficient is determined by the } \\
\text { variation degree of each index in the index } \\
\text { system, in order to reflect the influence degree } \\
\text { of any index to other indexes. }\end{array}$ & $\begin{array}{l}\text { Entropy method: weighted according to the } \\
\text { size of each index }\end{array}$ \\
\hline $\begin{array}{c}\text { Subjective and } \\
\text { objective } \\
\text { weighting } \\
\text { method }\end{array}$ & $\begin{array}{l}\text { The advantage of the characteristics of } \\
\text { subjective and objective comprehensive } \\
\text { weighting method, combined logically into two } \\
\text { kinds of methods, the weight coefficients of } \\
\text { both subjective and objective information }\end{array}$ & $\begin{array}{l}\text { Network analytic hierarchy process and } \\
\text { entropy weight method }\end{array}$ \\
\hline
\end{tabular}

2) Examples of application of weighting method

(1)Application example of subjective weighting method. Literature [41] used the analytic hierarchy process to determine the index of subjective judgment matrix to calculate the weight of evaluation index of the distribution network operation. In the process of comprehensive evaluation, the index weight is determined by using analytic hierarchy process, such as establishing judgment matrix, calculating weight and checking consistency ${ }^{[42]}$. Analytic hierarchy process is used as a method to evaluate the power system, and it has been widely used in the comprehensive evaluation of power system.

(2) Examples of the application of the objective weighting method. Literature [43] proposed a dynamic evaluation model of distribution network planning, according to each index in the evaluation period with the size of the amount of information to determine the weight of each index, and through the variation of system dynamics model to simulate the weight using the entropy weight method. Literature [44] based on interval analytic hierarchy analysis method and similarity to ideal solution TOPSIS ranking method of load density index calculation method, the similarity to ideal solution ranking method based method for the objective evaluation of performance indicators, through the difference between to be calculated in the load density index and its optimal performance, load density correction is proposed. For the evaluation method based on the position information of the index value, the typical representative is the ordered weighted averaging operator. In the literature [45], the optimal combination forecasting of short term load is carried out by using the induced ordered weighted averaging operator, and the corresponding weight coefficient optimization model is established. By sorting the prediction accuracy index value, the position weight of prediction accuracy is obtained.

(3) An example of the application of subjective and objective weighting method. Such as literature [46] on the network layer analysis method and entropy method combining subjective and objective weight determination method; literature [47] based on modified Delphi method of hierarchical analysis method, this method can better suitable for the weight of the evaluation index system of configuration; literature [48] by the cloud model improved AHP method to determine the subjective weight and entropy weight method to determine objective weights combination as the basic context; literature [49] 
established the regional power grid intelligent development level of the combined weight of the hierarchical optimization of composite evaluation optimization model based on, the weight of each identified by combining the subjective and objective weights of AHP and entropy method.

(2) The comprehensive evaluation method

1) On the grid for the comprehensive evaluation method is also a lot of, the whole can be into three categories: evaluation method of intelligent algorithm, the traditional algorithm evaluation method of class and multi algorithm combination evaluation method class, the three kinds of method comparison as shown in Table 4.

Table.4 Comparison of comprehensive evaluation methods

\begin{tabular}{|c|c|c|}
\hline $\begin{array}{l}\text { Comprehensive } \\
\text { evaluation method }\end{array}$ & Overview of methods & Typical methods and characteristics \\
\hline $\begin{array}{l}\text { Intelligent algorithm } \\
\text { evaluation method }\end{array}$ & $\begin{array}{l}\text { For multiple attribute comprehensive } \\
\text { evaluation of complex objects, in the } \\
\text { same type of indicator based on using } \\
\text { evaluation index without dimension data, } \\
\text { by means of artificial intelligence } \\
\text { learning, expert knowledge, established } \\
\text { by evaluation index attribute value to the } \\
\text { output value of comprehensive evaluation } \\
\text { of the nonlinear mapping relationship }\end{array}$ & $\begin{array}{l}\text { Neural network comprehensive evaluation } \\
\text { method: usually based on the fuzzy } \\
\text { mathematics membership function } \\
\text { description, the method of adaptive reflects } \\
\text { the interaction between the factors. At the } \\
\text { same time, the improved neural network } \\
\text { algorithm is also more widely used in the } \\
\text { field of network planning assessment, } \\
\text { power grid security model. }\end{array}$ \\
\hline $\begin{array}{l}\text { Traditional algorithm } \\
\text { evaluation method }\end{array}$ & $\begin{array}{l}\text { On the basis of explicit knowledge, the } \\
\text { algorithms that take the algorithm, } \\
\text { usually do not have the characteristics of } \\
\text { "adaptive" }\end{array}$ & $\begin{array}{l}\text { Principal component analysis: it is based on } \\
\text { the data analysis to get the intrinsic } \\
\text { structure relations between the indicators, } \\
\text { and not affected by the subjective factors, } \\
\text { the comprehensive indicators are } \\
\text { independent of each other. }\end{array}$ \\
\hline $\begin{array}{l}\text { Evaluation method of } \\
\text { multiple combination } \\
\text { algorithms }\end{array}$ & $\begin{array}{l}\text { The advantages of both methods, the } \\
\text { combination algorithm has good } \\
\text { performance }\end{array}$ & $\begin{array}{l}\text { The combination of factor analysis and } \\
\text { neural network }\end{array}$ \\
\hline
\end{tabular}

2) Examples of typical synthetic evaluation methods

(1) Principal component analysis

Principal component analysis method to determine the weights is based on data analysis of the inner relationship between the indexes and is not affected by the subjective factors and the comprehensive index independently of each other, so that the evaluation results with objectivity and accuracy, so in the assessment of power transmission network has been widely used. The literature [50] established the line loss index evaluation model based on principal component analysis, combining the theory of loss model optimization.

(2)Fuzzy comprehensive evaluation method

Fuzzy comprehensive evaluation method based on fuzzy mathematics. Fuzzy comprehensive evaluation model should be set up in the fuzzy comprehensive evaluation of electric power.

$$
B=\left(b_{1}, b_{2}, \ldots, b_{m}\right)=A o R=\left(a_{1}, a_{2}, \ldots, a_{n}\right) o\left[\begin{array}{cccc}
r_{11} & r_{12} & \ldots & r_{1 m} \\
r_{21} & r_{22} & \ldots & r_{2 m} \\
\ldots & \ldots & \ldots & \ldots \\
r_{n 1} & r_{n 2} & \ldots & r_{n m}
\end{array}\right] \text {. }
$$

In the model, $A$ for the weight set, $b_{j}$ for the membership degree of the evaluation object belongs to the first $j$ evaluation, $B$ belongs to the fuzzy set on the judgment set. $o$ means a composite operator.

The literature [51] established apply fuzzy comprehensive evaluation model for transmission network planning evaluation by the improvement of synthesis operator, makes full use of all the 
evaluation of each index, the evaluation results are more easy to identify. The literature [52] uses ANP method to determine the index weights, and then uses the fuzzy comprehensive evaluation method for comprehensive evaluation. Finally, the validity of the method is verified by examples.

\section{(3)Neural network method}

The neural network method is used for comprehensive evaluation, which is based on the description of the membership function of fuzzy mathematics ${ }^{[53]}$. Literature [54] using AHP and entropy method to determine the network planning project index weight, based on improved neural network evaluation method of power network planning project comprehensive evaluation model is established. Literature [55] based on BP neural network nonlinear and self-learning ability, the BP neural network model is established by using MATLAB, through the previous data of training for a power grid dispatching system of study, summed up the general rules, and through the network of reproduction, the new data made accurate evaluation, to achieve the desired effect. Literature ${ }^{[56]}$ utilization of the nonlinear mapping function of neural network, combined with the safety evaluation index system for the construction of, and collected by the State Grid Corporation of North China grid provides the transmission network each operation stage of the safety status of original data and to construct the applicable to transmission network of the BP neural network dynamic security assessment model and in the practical application verified the effectiveness and practicality of the method

\section{(4)Evaluation method of combination of various methods}

The evaluation method combined with various evaluation methods has many advantages, so it is widely used in power system evaluation. By using factor analysis method, the index system is analyzed and reduced, and the neural network security evaluation model of transmission network is constructed by the nonlinear mapping and self-learning ability of neural network. Verification results show that using the method of factor analysis and neural network are combined in the transmission network security situation of comprehensive evaluation, and reduced the number of evaluation index, and reduces the subjectivity of traditional evaluation methods, improve the objectivity and scientificity of the evaluation results ${ }^{[57]}$. Literature [58] used improved entropy weight method to determine the weights of evaluation indexes, with the grey relational analysis theory, is established based on Improved Entropy and grey relational analysis of smart grid comprehensive evaluation model, through the case illustrates the rationality of the method. In the literature [59], the AHP and fuzzy evaluation method are combined to get the weight of each layer factors and the comprehensive risk evaluation matrix, and combined with an example analysis. The current risk of China's smart grid is analyzed. The literature [60] combined with grey system theory and analytic hierarchy process to construct the sustainable evaluation method of power grid construction project.

\section{Discusion}

\section{The current situation of network evaluation}

From the foregoing, the scholars have made a lot of theoretical research and Empirical Analysis on the evaluation of power grid. These studies or for the overall level of power grid development were evaluation studies, or for a specific aspects of grid locality analysis, provide the basis and the reference for the level of development to effectively improve the grid, but there are still some problems:

1) Network assessment content is not comprehensive. Under the current assessment of power transmission network, the actual evaluation considered the dimension is not enough, as previously mentioned, the new electricity changed environment, grid assessment should be at least from the safety of power grid, power quality, sustainable development of the power grid and network operation efficiency and four dimensions. In addition, the need according to the actual situation of evaluation objects, in the assessment of the content added adaptability and coordination, equipment operation and management level and.

2) Lack of "self adaptation" in power grid evaluation. Due to the different evaluation objects, different regional power grid development time and speed of development, there is a difference in the 
development of demand. And now the power assessment, the lack of regional power network is their own development needs to consider, using only a set of evaluation method and evaluation system weights according to the assessment object adjust, unable to meet network evaluation " self adaptation " demand.

3) Lack of objectivity in the assessment of power grid. In the current assessment of China's power grid, the subjective factors still occupy a considerable share, and sometimes even in the power grid to occupy the leading role in the assessment. There are many reasons for the proportion of subjective factors, among which the most important reason is that in the process of power network evaluation, the methods adopted are mostly subjective methods or the method based on subjective factors.

\section{Possible research directions in the field of power network evaluation}

Overall, the domestic and international research result for our future grid assessment research provides a lot of theoretical basis and practical experience. However, as in 4.1, the current network evaluation still exist some problems and need our further development and perfection.

(1) Set up a complete set of evaluation index system for power grid

Under the environment of new electricity reform, the model should give full consideration to the assessment of power transmission network in a variety of uncertainty. It should be from the safety of power grid, grid power quality, grid sustainable development and network operation efficiency and four main dimensions to comprehensive evaluation of network development level. At the same time, according to the actual situation of the evaluation of network, the appropriate increased evaluation dimensions, such as increasing the dimension of the smart grid, the level of equipment, power grid structure and power supply, power grid coordinate the adaptive, operational management level. Here should pay attention to the problem as follows: 1) The choice of dimensions is not easy. According to the domestic and foreign scholars for many years of research, the four dimensions of grid security, grid power quality, grid sustainable development and network operation efficiency and is the main dimensions of network evaluation, is the most basic network evaluation dimensions, in the power grid assessment process should contain at least four dimension degrees. If you are less than the 4 dimensions of assessment will result in inaccurate assessment results. 2) The selection of dimension should not be too much. Power grid is a very complex system, which involves many and miscellaneous. Therefore, in the assessment of the power grid, it is impossible for us not to incorporate all the relevant aspects of the grid into the assessment of the power grid. Specific according to the actual situation, in the basic grid assessment system, the appropriate increase in the demand for the content can be.

(2) To study a set of evaluation methods of "self adaptation"

Different regions and different development stages of power grid development level gap are very huge, the evaluation of the characteristics of different needs, and its development needs are also different. Therefore, it is urgent to establish a set of effective evaluation index system of power grid development with "adaptive" property, and determine the weight of each index to evaluate the development level of regional power grid. Using intelligent algorithm research establishes the calculation method and calculation model of dynamic evaluation index weights, can be conducive to the objective evaluation of different regions, different stages of development exists grid, and the grid investment benefit, for different regions, different development stages of power grid management assessment provides scientific basis, and subsequent power grid planning and construction of power grids project reasonable arrangements to provide decision-making reference.

Research on adaptive weights and comprehensive evaluation on the development of regional power grid will be of great significance to promote the development of power grid: 1) to meet their own needs, different areas of the proposed specific measures and suggestions to promote the development of the power grid; 2) with different stages of development needs, to be able to measure and suggestion characteristics in different stages of development; 3) to actively promote the coordinated development of the power grid, and help the analysis of the current situation of grid in the professional problems, and the formation of quantitative related measures and suggestions, and actively promote the coordinated development of power grid; 4) helps to improve the efficiency and 
benefit of power grid operation, to avoid duplication of investment, excessive investment in advance of power grid, which can effectively improve the efficiency and effect of power grid operation.

\section{Acknowledgements}

This work was financially supported by the engineering project of State Grid Zhejiang Electric Power Company named study on the adaptive weight system of the power grid evaluation indexes.

\section{References}

[1] Cui Yanyan. Grid Planning and Evaluation Method of application [D]. Tianjin University, 2008.

[2] Huangchen Hong, Tang Yun Xu, Liu Jun, Present situation and construction method of statistical index system of domestic and foreign intelligent power grid [J]. East China Electric Power, 2011 (12): 1981-1985.

[3] Ji Yuan, Huang Yusong. Evaluation Method on comprehensive smart grid [J]. Electrical Engineering, 2015, 34 (3): 81-84.

[4] Zhang Hairui. Study on the comprehensive evaluation method of smart grid [D]. Shanghai Jiao Tong University, 2012.

[5] Haixia Gao, Research and application of evaluation method of urban medium voltage distribution network [D]. Tianjin University, 2007.

[6] Ma Junhua, LU Yan-sheng, Yue Zhendong. Based Network Security rough set theory [J] Wuhan University: Engineering Science, 2009, 42 (3): 377-381.

[7] Sridhar S, Hahn A, Govindarasu M. Cyber-physical system security for the electric power grid [J]. Proceedings of the IEEE, 2012, 100(1): 210-224.

[8] Ming Z, Shi D, Song X, et al. Indices System and Methods for Power Grid Security Assessment Based on Dynamic Fuzzy[C]//Electrical and Control Engineering (ICECE), 2010 International Conference on. IEEE, 2010: 3830-3833.

[9] Houli Li, Xu Fan. Based on smart grid a safety evaluation AHP Law of Entropy [J]. Modern Electric Power, 2011, 28 (5).

[10]Niu Dongxiao, Wei Yanan, Mian Xing. Analysis and application of safety evaluation system for power grid operation [J] East China Electric Power, 2010 (002): 160-163.

[11]Wang Zheng, Liu Guohai, Shen Yue, et al. Research on power quality monitoring system based on LabVIEW and its data storage format. Electrical measurement and instrumentation, 2013, 50 (6): 83-87.

[12]Huang Dehua, Yu Tao, Zhang xing. Design and implementation of power quality monitoring and advanced analysis software platform for distribution network [J]. Power system protection and control, 2013, 3: 26

[13]Wei Yongzhong, Zheng Aixia, Yuan Xiaodong. Evaluation method and application of power quality of Jiangsu power grid [J]. Jiangsu electric engineering, 2011, 30 (5): 1-4.

[14]Zhao Liang, Liang Dong, Zhang Jianjun. Analysis of power quality assessment methods [J]. High voltage electrical equipment, 2012, 48 (007): 27-30.

[15]Sun Yueguo, Li Liying. Modeling and Simulation of power system reliability evaluation [J]. Computer simulation, 2012, 4: 84.

[16] Wang Guangqiang, Xie Kaigui, Hu Bo. A class tree algorithm for reliability evaluation of medium voltage distribution network [J]. Power system technology, 2011, 35 (12): 77-82.

[17]Song Yunting, Wu Junling, Peng Dong. Prediction method of power supply reliability of urban power network based on BP neural network [J]. Power system technology, 2008, 32 (20): 56-59.

[18] Xiang li. The protection of environmental standards and management to promote the harmonious and sustainable development of power grid [J]. Environmental protection, 2013, 41 (015): 27-29.

[19] Li Li, Lei Yu, Ge Xubo. Index system and evaluation method of sustainable development of power grid enterprises [J]. Journal of electric power, 2007, 1: 000.

[20] Xu Hua, Zou Hongliang. Study on the sustainable development of urban power network based on state space and entropy weight [J]. East China electric power, 2011, 39 (12): 1985-1988.

[21] Han Liu, Peng Dong, Wang Zhidong. Construction and application of power grid evaluation index system [J]. Electric power construction, 2010, 31 (11): 28-33.

[22] Xiao Jun, Cui Yanyan, Wang. Distribution network planning the comprehensive evaluation index system and method [J]. Automation of electric power systems, 2008, 32 (15): 36-40.

[23] Yao Yao. Comprehensive evaluation index system and method for distribution network planning [J]. China new technology and new products, 2015 (23): 42-42. 
[24]Liu Lianguang, Chen Wei, Liu Zifa. Evaluation problems and evaluation system of large power network adaptability [J]. Electric power construction, 2015, 36 (10): 138-143

[25] Wang Bin, He Guangyu, Mei Shengwei, et al. Construction method of smart grid evaluation index system [J]. Automation of electric power systems, 2011, 35 (23): 1-5.

[26] Wang Zhidong, Huang Yi, Jin Xiaoling. Study on the evaluation index system of China's power grid development [J]. Journal of Northeast Dianli University: Social Science Edition, 2009, 29 (4): 83-86.

[27]Ni Jingmin, He Guangyu, Shen Chen, et al. Review of the American smart grid evaluation [J]. Automation of electric power systems, 2010, 34 (8): 9-13

[28]Lv Pengpeng, Zhao Jinquan, Li Duanchao, et al. Evaluation index system and comprehensive evaluation method for power system operation state [J]. Power system technology, 2015, 39 (8): 2245-2252.

[29]Zhang Xinjie. Intelligent distribution network comprehensive evaluation system and method [D]. Tianjin University, Liu Manping 2013. The core of the new electricity reform program, focus on and [J]. Macroeconomic management 2015 (6): 20-22.

[30]Liu Manping. Core, focus and influence of the new scheme of electric power reform [J]. Macro-economic management, 2015 (6): 20-22.

[31]Bian Erchao.Regional power grid development level diagnosis system and Application Research [D]. North China Electric Power University, 2014

[32] Anderson G, Donalek P, Farmer R, et al. Causes of the 2003 major grid blackouts in North America and Europe, and recommended means to improve system dynamic performance[J]. IEEE Transactions on Power Systems, 2005, 20 (4): 1922-1928.

[33]Li Chunyan, Sun Yuanzhang, Chen Xiangyi. Analysis of the blackout in Europe on November 4, 2006[C]. //Power Engineering Conference, 2007: 939-944.

[34]Bai Mei. The logical starting point and the policy implications of the new electricity reform program [J]. Price theory and practice, 2015 (6): 8-13.

[35] Hu Antai, Xiao Jun, Luo Fengzhang. The economic evaluation for electricity, application of [J]. Power supply, 2005, 22 (3): 9-11.

[36] Yu Huiping, Liu Jidong, Cheng Haozhong, et al. Study on cost effectiveness analysis and evaluation of power grid planning [J]. Power system technology, 2001, 25 (7): 32-35.

[37] Li Jian. Comprehensive evaluation of operation performance of power grid enterprise [D]. North China Electric Power University, 2013.

[38] Sun Yanlong, Kang Chongqing, Chen Songsong. Evaluation index system and method for low carbon power system [J]. Automation of electric power systems, 2014, 38 (17): 157-162.

[39]Zhou Lisha. Key indicators of smart grid low carbon benefits selection and evaluation of [D]. Model of North China Electric Power University, 2013.

[40] Ye Yun. Study and application of comprehensive evaluation method for distribution network [D]. Chongqing University, 2011.

[41]Jan Xuedan. Distribution network economic operation of the AHP Fuzzy Comprehensive Evaluation Based on [D]. Yanshan University, 2013.

[42] Yuan Xiang. SG transmission network operation economic evaluation system construction and operation optimization [D]. South China University of Technology, 2013.

[43] Gu Jie, Qin Yue Hailong Bao. Based on entropy weight with the system dynamics, the dynamic distribution network planning comprehensive evaluation. Electric power system protection and control, 2013, 41 (1): 76-83.

[44]Liu Zifa, Wei Jianwei. Based on IAHP and TOPSIS method of load density index calculation. Automation of electric power systems, 2012, 36 (13): 56-60.

[45]Li Jinghua, Wei Hua. Based on induced ordered weighted averaging operator of the optimal combined short-term load forecasting [J]. Power system technology, 2011, 35 (10):177-182.

[46] Xu Xin. Study on the comprehensive evaluation system of intelligent power grid based on the combination evaluation theory [D]. North China Electric Power University, 2012.

[47]Qiang Ding Jian. Study on the comprehensive evaluation system of distribution network planning considering micro grid [D]. Zhejiang University, 2014.

[48] Xu Zhifen. Study on low carbon benefit evaluation of regional smart grid [D]. North China Electric Power University, 2014

[49]Tang Hui. Study on comprehensive evaluation of regional power grid intelligence development level [D]. North China Electric Power University (Beijing), 2011.

[50]Lu Jiaming, Gao Jie. The principal component analysis of the line loss index evaluation based on [J]. East China electric power, 2014, 09. 
[51]Nie Hongzhan, Lu Pan, Qiao Yi. The entropy weight method of transmission network planning based on fuzzy comprehensive evaluation [J]. Power system technology, 2009, 11 period (11): 60-64.

[52]Xu Zhiyong, Zhang Xudong, Zeng Ming, et al. Study on the post evaluation of power grid construction project based on ANP fuzzy comprehensive evaluation method [J]. East China electric power, 2009, 03: 488-491.

[53]Pan Dafeng, Li Qun. Research on multi index comprehensive evaluation method of neural network [J]. Agricultural system science and comprehensive research, 1999, 02: 105-107.

[54]Zhang Jie. Study on comprehensive evaluation of power grid planning based on improved neural network [D]. North China Electric Power University (Hebei), 2008.

[55]Wang Lixia, Hua Shuai, Liang Jinyan, et al. Safety evaluation of power network dispatching system based on BP neural network [J]. Safety and environmental engineering, 2013, 06: 126-129.

[56] Mao Zhijie. Study on safety evaluation method of transmission network based on artificial neural network [D]. Henan University of Science and Technology, 2009.

[57] Yang Zongxiao, Mao Zhijie, Yang Benbo, et al. Based on factor analysis and neural network security evaluation of transmission network [J]. Power system technology, 2009, 14 (14): 31-36.

[58]Zhang Hong. The comprehensive evaluation and improvement of smart grid entropy and gray correlation analysis based on [J]. Journal of Liupanshui Normal College, 2015.

[59]Zeng Ming, Chen Yingjie, Hu Xianzhong, et al. Risk assessment of China's smart grid based on multi hierarchy fuzzy comprehensive evaluation [J]. East China electric power, 2011, 04 (4): 535-539.

[60] Bai Jianguo. Study on sustainable evaluation model and application of power grid construction [D]. North China Electric Power University, 2012. 